\title{
Relationships between the Advertising Appeal and Behavioral Intention: The Mediating role of the Attitude towards Advertising Appeal
}

\author{
Syed Hassan Raza ${ }^{1, *}$, Hassan Abu Bakar ${ }^{2}$, and Bahtiar Mohamad ${ }^{3}$ \\ ${ }^{1}$ School of Multimedia Technology \& Communication, 06010 UUM Sintok, Kedah, Malaysia/ \\ Lecturer Bahauddin Zakariya University, Multan, Pakistan \\ ${ }^{2,3}$ Department of Communication, School of Multimedia Technology \& Communication, 06010 UUM \\ Sintok, Kedah, Malaysia
}

\begin{abstract}
The link between the advertising appeal, attitude and behavioral intention is dynamic in nature, however, little research has been pursued towards explaining the mediating role of attitude towards the advertising in link of the advertising appeal with the behavioral intention. Researchers have identified the importance of the attitude in the connection of the advertising appeal within the framework of the (TPB) which remains unaddressed in the explicating the mediation of the attitude in relationship of advertising appeal and behavioral intention. This paper aims to provide insight of the attitude towards the advertising as the mediating factor in explaining the relationship between the advertising appeal and behavioral intention. In addition, this paper is only a theoretical exploration, it is expected that this work lead towards an explanation of the mediating role of the attitude to address the relation of advertising appeal and intention which may be studied further to determine the empirical finding about the other dynamic of the (TPB).
\end{abstract}

\section{Introduction}

Despite, the fact that the dynamic relation of attitude and Advertising appeal is widely explained in the body of the literature in different perspectives, but remains less clear with the mediating aspect of the attitude in relationship of advertising appeals and behavioral attention [1-2]. Hence, the connection of the attitude with the behavioral intention and its effect in the sphere of advertising is consistency with the Theory of Planned Behavior (TPB) [3-4]. Thus, it remains minimal attention paid in the literature to address the issue how the dynamics of attitude mediate the relationship between Advertising appeals and to predict behavioral intention.

Moreover, in the previous studies mediation of the attitude to the Advertising appeal towards the behavioral intention is specifically based on the attitude towards advertising brand or product [5]. Therefore, it remains lack of the systematic inquiry in the context of the empirical explaining the mediation of the attitude to predict the behavioral intention and

* Corresponding author: sherazibzu@gmail.com 
Advertising appeal [5]. Previous literature indicates that attitude does not solely predict the behavioral intention in consistent with the theory of planned behavior, where as there are many antecedents of attitude which are explored in the past studies towards behavioral intention but remains detached [6]. The link between the advertising appeal, attitude and behavioral intention is dynamic in nature [7]. Consequently, mediation of attitude in the Advertising appeal and behavioral intention lacks empirical evidence in the body of knowledge as less attention is paid towards this specific dimension which is the contribution of this study.

Thus, mediating role of the attitude in predicting behavior intention can be determined altogether with the message contained in the advertising and its appeal [8]. Therefore, it provides another argument to investigate the mediating direction of attitude towards predicting behavioral intention as it is affected by the Advertising appeal but remains minimal in the past literature. Sallam and Wahid, [9] noted that advertising effects on behavioral intention is routed through the attitude as it serves as the mediating factor between the behavioral intention and Advertising appeal.

\section{Review of Literature}

\subsection{Theory of planned behavior}

In explaining the relationship of attitude and behavioral intention key concepts, the Theory of Planned Behavior (TPB) proposed by the Ajzen and his contemporaries discussed that the relationship of attitude and behavioral intention serves as a wide range of explanations and predictions towards the behavioral intentions on the account of the attitude $[3,4,10,12]$. TPB hypothesizes that, on the description of the accuracy of the attitude contribute as a potential antecedent to predict the behavioral intention. Therefore, behavioral intention is considered as the depending factor on the motivation and likeness emphasize by the measure of the attitude and premise behavioral intention as a rationale process in which individual's course and make use of the presented information to reach at a intention consideration [10-12].

What's more the previous studies indicate, there is a variety of the inconsistency in the results of relationship between the attitude and behavioral intention in terms of contradictory in variance which suggests to conduct more research and contribution in this area [13-16]. Armitage and Conner [14] found after the Meta-analysis of 185 previous studies carried out on the TPB and found variance ranging from $27 \%$ t0 $39 \%$. Furthermore, he suggests that additional investigations are essential to give improved understanding and explanation of the other potential factors which may involve in the relationship of TPB key constructs. Therefore, this current article addresses the aforesaid issue as a contribution to test the important forerunner factors like Advertising appeal involved in the development of the attitude-behavioral intention link.

\subsection{Advertising appeal and attitude}

Advertising appeal is the defined as the management and arrangement of the advertisements to the potential purchasers [17]. Advertising appeal is also considered as the key objective of the advertising as it tempted to give appeal to the targeted audience. The Advertising appeal is given by several modes of the advertising ranging from the television advertising to the billboards. Therefore, this is also the aim of the any advertiser to enhance the number of the Advertising appeal as it can probably increase the frequency to attain the 
basic objectives of the advertising [18]. Furthermore, repetitive Advertising appeal help to seek the objective to motivate the consumers to pursue towards the product or the services desired by the advertiser as it directly affects the attitude of the individual by manipulating ideas [19].

Whereas, attitude is considered as an expression of the goodwill or the disapproval for the thing, idea or the person. Attitude is also described as the position of the individual based on its internal evaluation in respect of the tendency or the orientation towards the person, character or the object and depends on the experiences and motivation [9]. Furthermore, attitude differs on the bases of the motivation asked towards the specific stimulus in the form of an idea, person or product so that the attitude formulation is highly dependent on the position of the asked phenomena. Therefore, the attitude of an individual learns and gets affect from the Advertising appeal as it motivates the individual towards the desired position of the attitude by the manipulating the thinking of an individual [20].

Past research has also suggested that the advertising impacts the attitude of the audience due to the persuasive nature of the advertising. Furthermore, Advertising appeal leads the attitude which indeed affects the behavioral intention [21]. However, Inadequate inquiries have been done in the past to address the relationship of the attitude as a driver of behavioral intention in result of Advertising appeal [13-22]. Advertising appeal can be the potential influential factor in the development of the behavioral intention as it has a direct effect on the attitude, but it remained unclear in the past literature as systematic inquiry is needed to understand this mediated relationship.

Therefore, on the basis of the above mentioned literature, it may be postulated that attitude and Advertising appeal have direct dynamic link to define the relationship of advertising and behavioral intention as it remains an uncertain issue in the research. Hence, if the relationship of attitude and the Advertising appeal positive it positively affects the behavioral intention, we would expect that at the same time if it is negative it can affect vice versa. Thus we propose the following preposition.

Preposition 1: There is a direct positive relationship between Advertising appeal and attitude.

\subsection{Attitude and behavioral intention}

Behavioral intention is defined as the individual's perceived chance of the likeness or subjective prospect to adopt or engage in the certain behavior. Moreover, it is supposed as the instant forerunner of the behavior as it designates the individual's willingness to execute the certain behavior [23]. Furthermore, behavioral intention is also considered as the particular predictor of an individual's behavior, but on the other hand formulation of the behavioral intention depends on some predictors as mention in the (TPB), the attitude towards the behavior is one of the significant predictor of the intention [24].

Despite the fact that the direct relationship of attitude and behavioral intention is highly examined and in many previous studies [25-27] and found it significant. While on the other hand, there is enough evident literature which indicates the role of certain antecedents to formulate the attitude towards the intention [28-29]. Thus, these facts improve the initiative to examine the mediating role of attitude in to explain the relationship of behavioral intention with the factors involved in the attitude formation like the Advertising appeal. Therefore, to explain the said phenomena we propose that:

Preposition 2: There is a positive relationship between attitude and behavioral intention. 


\subsection{Advertising appeal and behavioral intention}

There are enough traces in the literature providing evidence to understand and explain the relationship between advertising and behavioral intention[26,30,31] however, at the same time it remains less explanatory in term of mediation of the attitude in the dynamic link between both concepts $[10,32,34]$. In previous studies it is found that Advertising appeal results to have positive behavioral intention as it positively influence the attitude or vice versa which is evident of the fact that there is a link between advertising and behavioral intention with the mediation or facilitation of the attitude which need more explanation by considering it for further empirical research [35].

It is indicated in a study that the elements of the advertising like information to the people about the advertised thing or idea work in the positive direction to have an influence on the behavioral intention of the people. He also suggested that the perspectives of the entertainment and credibility of the advertising results significant effect on the behavioral intention, but he also found some other factors which may influence the relationship of Advertising appeal and intent. Therefore, it may be assumed on the basis of many studies accessible in the previous literature which indicated involvement of certain factors like attitude as the predictor or mediator between the link of the Advertising appeal and behavioral intention but remains detached [36]. Based on this, we propose that:

Preposition 3: There is a positive relationship between the Advertising appeal and behavioral intention.

\subsection{Attitude as Mediation}

The attitude of the individual is the essential determinant of the behavioral intention as it serve as the considerable predictor of it as suggested in (TPB), but at the same time it is also found in studies of many researchers that it is a significant fact that attitude also have role to explain the relation of the behavioral intention and Advertising appeal $[20,36,37]$. There is enough evidence about the effects of antecedents on attitude towards the intention within the framework of (TPB) which strengthen the idea of attitude's mediation inquiry in connection of the Advertising appeal and intent [11,16,25,38]. However, no empirical compilation and enough studies in the past have been done to explain the mediating role of the attitude in the connection of the Advertising appeal to the behavioral intention which is proposed in this current study. Based on this, we propose that:

Preposition 4: The relationship between the Advertising appeal and behavioral intention is mediated by attitude.

On the basis of the above arguments, we propose the following preposition. 


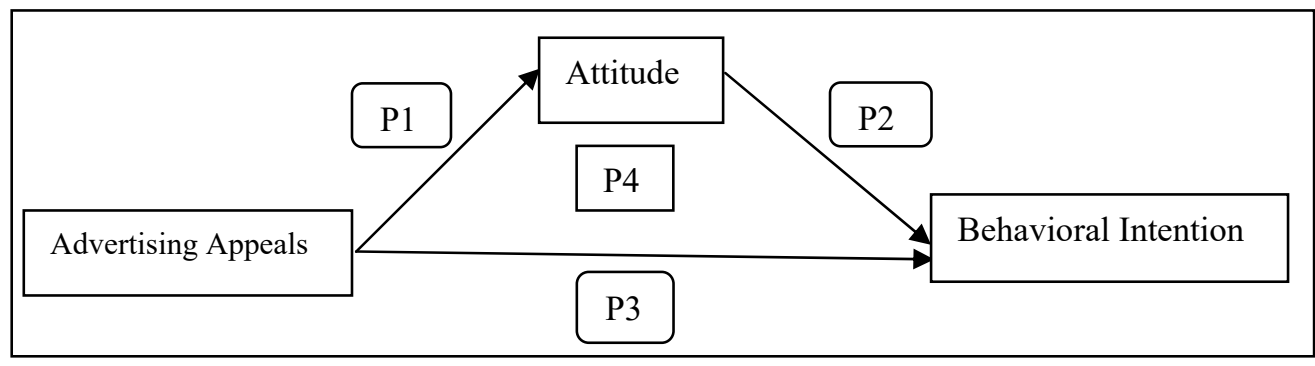

Fig. 1 Proposed Model of Mediation of Attitude in relationship of Advertising and Behavioral Intention.

\section{References}

1. U. C. Eze and C. H. Lee, Int. J. Bus. Manag., 7, 94-108, (2012)

2. E. Kaynak, A. Kara, and C. S. F. Chow, J. Asia-Pacific Bus., 14, 88-106, (2013)

3. I. Ajzen, Psychol. Health, 26, 1113-1127, (2011)

4. I. Ajzen, Orgnizational Behav. Hum. Decis. Process., 50, 179-211, (1991)

5. L. Zarantonello and B. H. Schmitt, J. Brand Manag., 17, 532-540, 2010.

6. M. G. Kenney and N. M. Khanfar, Serv. Mark. Q., 30, (2015)

7. J. D. Martín-Santana and A. Beerli-Palacio, J. Euromarketing, 17, 159-181, (2008)

8. U. R. Orth, H. F. Koenig, and Z. Firbasova, Eur. J. Mark., 41,327-348, (2007)

9. M. A. A. Sallam and N. A. Wahid, Int. Bus. Res., 5, 55-66, (2012)

10. I. J. Donald, S. R. Cooper, and S. M. Conchie, J. Environ. Psychol., 40, 39-48, (2014)

11. M. F. Chen and P. J. Tung, Int. J. Hosp. Manag., 36, 221-230, (2014)

12. R. J. Vallerand, P. Deshaies, J.-P. Cuerrier, L. G. Pelletier, and Et Al, Journal of Personality and Social Psychology, 62, 98-109, (1992)

13. L. R. Glasman and D. Albarracín, Psychol. Bull., 132, 778-822, (2006)

14. C. J. Armitage and M. Conner, Br. J. Soc. Psychol., 40, (2001)

15. T. L. Webb and P. Sheeran, Psychol. Bull., 132, 249-268, (2006)

16. G.-J. de Bruijn, K. Verkooijen, N. K. de Vries, and B. van den Putte, Psychol. Sport Exerc., 13, 771-778, (2012)

17. S. Schmidt and M. Eisend,J. Advert.,14, (2015)

18. K. Y. Wang, E. Shih, and L. a. Peracchio,Int. J. Advert.,32, (2013)

19. W. D. Crano and R. Prislin, Attitudes and attitude change. 18, (2008)

20. C. Dianoux, Z. Linhart, and L. Vnouckova, J. Compet.,6, 87-103, (2014)

21. A. Morris and L. A. Kahlor, Howard J. Commun., 25, 415-430, (2014)

22. H. N. T. E.Ma.Tsung-kuang, J.Y Dong, Int. J. Organ. Innov., 2,190-198, (2009)

23. B. Kidwell, Adv. Consum. Res. Consum. Res., 34, (2007)

24. S. E. Zemore and I. Ajzen, J. Subst. Abuse Treat., 46, 174-182, (2014)

25. B. Schreurs, E. Derous, E. a J. van Hooft, K. Proost, and K. de Witte, J. Organ. Behav., 30, pp. 761-783, (2009)

26. W.-H. Hsiao and T.-S. Chang, Behav. Inf. Technol., 33,730-742, (2013)

27. C. R. Nigg, S. Lippke, and J. E. Maddock, Psychol. Sport Exerc., 10, 219-225, (2009)

28. O. M. \& N. L. R. Peter, Int. J. Soc. Sci. Enterpreneursh., 3, (2014)

29. D. Sari and B. Kusuma, Asian Mark. J., 6, 50-63, (2014)

30. A. Muk and C. Chung, J. Bus. Res., 68, (2014)

31. Y. J. Kim, D. Njite, and M. Hancer, Int. J. Hosp. Manag., 34, 255-262, (2013)

32. J. I. Rojas-Méndez, G. Davies, and C. Madran, J. Bus. Res., 62, 947-954, (2009)

33. Y. Wang and S. Sun, Int. Bus. Rev., 19, 333-344, (2010) 
34. M. de Mooij and G. Hofstede, Int. J. Advert., 29, 85-110, (2010)

35. S. D. Myers, M. B. Royne, and G. D. Deitz, J. Public Policy Mark., 30, 110-118, (2011)

36. Ling, K. C., Piew, T. H., \& Chai, L. T. Canadian social science, 6(4), 114-126.(2010)

37. A. Tehrani and A. G. Tehrani, J. Bus. Manag. Rev., 3, 54-67, (2014)

38. H. H. Cheng and S. W. Huang, Int. J. Inf. Manage., 33, (2013) 